\title{
Four Dimensions of Self-Defining Memories (Specificity, Meaning, Content, and Affect) and Their Relationships to Self-Restraint, Distress, and Repressive Defensiveness
}

\author{
Pavel S. Blagov \\ Emory University \\ Jefferson A. Singer \\ Connecticut College
}

\begin{abstract}
This study examines four dimensions of self-defining memory (specificity, meaning, content, and affect) and their relationship to self-restraint, distress, and defensiveness. The development and validation of a protocol for measuring specificity, meaning, and affect in selfdefining memories is discussed. Specificity is operationalized as the temporal and detailed specificity of the narrative. Meaning refers to the participant's stepping back from the narrative to derive higher personal meaning or a life lesson. Affect reflects subjective emotion upon recall. Agreement between two raters scoring 1040 memories was $\kappa=.83$ for specificity and $\kappa=.72$ for meaning. The protocol is compatible with Thorne and McLean's scoring system for content (the types of events in memories). The current study compared individual differences in the four dimensions of 10 self-defining memories collected from 103 undergraduates to scores of self-restraint, distress, and repressive defensiveness, as measured by the Weinberger Adjustment Inventory. Memory specificity was inversely related to repressive defensiveness, while greater memory meaning was linked to moderate and high levels of self-restraint. Memory content and affect predicted individuals' degree of subjective distress. Based on these findings, the authors discuss the place of self-defining

Correspondence regarding this article should be addressed to: Jefferson A. Singer, Box 5586, Psychology Department, Connecticut College, 270 Mohegan Avenue, New London, CT 06320. E-mail: jasin@conncoll.edu
\end{abstract}

Journal of Personality 72:3, June 2004.

Blackwell Publishing 2004 
memories in Conway and Pleydell-Pearce's Self-Memory System model of autobiographical memory and personality, more generally.

In the course of an afternoon, a clinical psychologist sees two young adult clients for initial interviews in psychotherapy. Though her history-taking questions for each new client are essentially the same, the content and manner in which they recount narrative memories of their lives differ markedly. The first client, a 21-year-old man, complaining of mild depressive symptoms, when asked about a significant memory from his high school years, reports the following narrative:

I started to screw up in high school. Things began to go downhill, and I got really frustrated with myself. My parents were angry with me too for not living up to my potential. I did start to put more effort in after a while, and eventually, my grades got much better.

Other memories about his relationships with peers, his intimate relationships, and his first experiences in the workplace follow the same pattern in which the content of the memory is about failure or loss, the narrative quality of the memory is vague and minimally detailed, the affective tone of the memory is flat or mildly negative, and no effort is made to interpret or make sense of the experience.

The second client, a 19-year-old female, also reporting mild depressive symptoms, chooses a similar memory:

One night after I had done poorly on a mid-term math exam my junior year, I went for a walk on a trail near my house. In the cold February air, I thought about what my priorities were and why I had failed. I still remember that chilling feeling of that night, and ever since then, I have made a commitment to keep track of my schoolwork and not get distracted by less important things.

In the course of her interview, her other memories parallel this one; they often refer to frustration or loss, are rich in specific details and imagery, convey strong enduring affect, and are accompanied by introspective analysis and reflection.

Superficially, both clients present with depression and have recounted a series of memories that reflect their current dysphoric mood and preoccupation with negative life experiences. In fact, their 
scores on a brief screening device for depression locate them within the same range of mild dysthymia. Yet the manner in which they have narrated their remembered experience, and the degree to which they have integrated these experiences in their self-understanding, suggest a marked difference in both their openness to therapy and their overall personal adjustment. The first client displays a closed or defensive approach to his recollections and little insight about their meaning. The second client, though also recounting negative episodes, acknowledges the emotion they generate, and then attempts to extract lessons that possess ongoing importance for her life. Is it possible, then, that these variations in narrative memory, what McAdams (1995) would call the third level of "life story or identity" in his framework of personality, reflect more stable individual differences in trait-like constructs, such as defensiveness or adjustment?

In this article, we demonstrate reliable methods for scoring the four dimensions reflected in these two young adults' narrative memories - specificity, integrative meaning, event content, and affect. We then link these dimensions to personality measures of defensiveness, self-restraint, and life distress. It is our contention that the ability to identify patterns across memory narratives provides a window into understanding variation in basic personality processes. It may also ultimately lead to effective tools for personality assessment in psychotherapy.

In order to study narrative memories of the kind that might be raised in an initial clinical interview or subsequent history-taking sessions, we asked college student participants to recall a series of "self-defining memories." Previous research has examined these selfdefining memories (Singer \& Moffitt, 1991-1992) in the context of individuals' ongoing life goals (Moffitt \& Singer, 1994), the outcomes of current personal concerns (Jardine, 1999), and their intimate disclosures to others (McLean \& Thorne, in press). A self-defining memory is a highly significant personal memory that can be characterized by the following properties: It evokes strong emotion at the time of recollection. It is vivid in the mind's eye, filled with sensory detail, like a snapshot or video clip. It becomes a repeated touchstone in consciousness that we actively retrieve in certain situations or that returns to us unbidden (Salaman, 1970). It is representative of other memories that share its plot line, emotions, and themes. Though it is the most central one in a set of memories, it 
is highly linked to related memories. Finally, self-defining memories revolve around the most important concerns and conflicts in our lives - for example, unrequited loves, sibling rivalries, successes and failures, moments of insight and disillusionment.

Over the last two decades, our efforts to study the different aspects of self-defining memories have culminated in a comprehensive scoring system that provides the background, instructions, reliability data and sample memories for capturing the dimensions of specificity, integrative meaning, and affect (Singer \& Blagov, 2000). Thorne and McLean (2001; McLean \& Thorne, in press) have now added an event-content scoring system for self-defining memories that we have adopted and used with success as well. Though more detail on these scoring systems will be provided later in this paper, we briefly review background related to each dimension in the sections that follow.

The dimension of specificity. A recent comprehensive model of autobiographical memory (Conway \& Pleydell-Pearce, 2000) has emphasized that autobiographical memories are reconstructed through a hierarchical retrieval process that builds memories across three levels of organizational detail. Autobiographical knowledge may be slotted in general phases or stages of life ("lifetime periods"); in more narrow and theme-oriented timelines consisting of months, weeks, or days ("general events"); or it may possess specific imagistic qualities tied to a given moment in time ("event-specific knowledge"). When seeking a memory, individuals typically move from a general abstract level to the more specific, ultimately uniting all three levels to create the fully realized autobiographical memory. This memory is strongly linked to goals active in what Conway and Pleydell-Pearce call the "Self-Memory System" (SMS).

It has been proposed that individual variation in the specificity of memory recall can be related to individual differences in personality (Singer \& Blagov, in press a; Singer \& Salovey, 1993; Williams \& Broadbent, 1986). In a series of studies, Williams and his colleagues have found that severely depressed individuals have great difficulty recalling positive memories of specific events from their lives (Moore, Watts, \& Williams, 1988; Williams \& Broadbent, 1986; Williams \& Dritschel, 1988; Williams \& Scott, 1988). Moffitt, Singer, Nelligan, Carlson, and Vyse (1994) corroborated these findings in a sample of dysphoric undergraduates. Overgeneralization in positive and negative memory recall may also be linked to poor antidepres- 
sant therapy outcomes (Brittlebank, Scott, Williams, \& Ferrier, 1993).

In agreement with the Conway \& Pleydell-Pearce's SMS model, Williams proposed that since autobiographical memories are accessed first through abstract categories and greater effort is required to reach for specific detail, a working memory deficit (due to childhood trauma, depression, brain damage, or aging) may impair retrieval and lead to overgeneralization and a lack of specificity in autobiographical memories.

Singer and Salovey (1993) suggested that another source of overgenerality might be repression or the blockage of negatively toned information from consciousness. They reported preliminary data linking a repressive personality style to inhibited specific recall, suggesting that the imagery of specific narratives triggers intense and discrete emotional responses that repressive individuals may seek to avoid. Davis and Schwartz (1987) also found that individuals who score high on an inventory of repression recalled fewer affective memories and also tended to recall memories that were from more recent periods in their lives.

Thus, two different possibilities, which are not necessarily mutually exclusive, may exist about the relationship of memory specificity to personality. As Williams suggests, overgeneral memories may reflect a working memory deficit influenced by depression or other cognitive-emotional disturbance. Alternatively, overgeneral memories may be linked to a defensive avoidance of emotional arousal associated with the imagery generated by a more specific and detailed memory.

The measurement of memory specificity has differed across previous studies. In some cases the latency for specific autobiographical memory retrieval has been measured; in other cases, participants' inability to retrieve a specific autobiographical memory has been the variable in question. In studies from our laboratory, using written narratives, we have relied on a coding system that differentiates between specific and summary memory narratives (Singer \& Moffitt, 1991-1992). In the current investigation, we have refined this coding system and updated it to be more compatible with Conway and Pleydell-Pearce's (2000) SMS model.

The dimension of integrative meaning. Narrative processing, or the creation of a narrated experience, may be distinguished from autobiographical reasoning (Singer \& Bluck, 2001) or life reflection 
(Staudinger, 2001), which is the derivation of meaning (interpretations, evaluations, insights, explanations, and lessons) from memory and life narratives. In other words, people may convert memories into stories that they narrate internally or to others, but whether or not they attach a moral or lesson to the memory is a separate cognitive process. Theorists (e.g., Robinson, 1986) have suggested that the creation of meaning from memory assists affect regulation and communication in intimate relationships. Making meaning of past struggles and sharing this insight has been found to predict positive self-regard in college students (Debats, Drost, \& Hansen, 1995), less grief over time in bereaved spouses (Bauer \& Bonanno, 2001), and well-being, a sense of growth, and enhanced ego development in parents of disabled children (King, Scollon, Ramsey, \& May, 2000).

In agreement with Pillemer (1998), and the work of Thorne and McLean (see this issue), Singer and Blagov (2000) have developed the more general construct of integrative memories, narratives in which individuals take the additional step of ascribing meaning to their memories by relating them to lessons about the self, important relationships, or life in general. We have proposed (Singer \& Blagov, in press a) that the meaning-making process in the construction of self-defining memories enables memory to affect the self. Not only do life goals influence the construction of autobiographical memory (Conway \& Pleydell-Pearce, 2000), but linking memories to abstract self knowledge through meaning making creates a positive feedback loop that gives additional cognitive, affective, and motivational value to the memory and powerfully reinforces relevant goals (Singer \& Blagov, in press a).

The capacity to learn from experience and to incorporate these life lessons into ongoing self-knowledge is certainly one of the prized goals of any psychotherapy, whether insight-oriented or cognitivebehavioral. Accordingly, the ability to generate integrative meanings from narrative memory should be associated with higher levels of socioemotional maturity and personal adjustment. Staudinger and other researchers have demonstrated that life reflection is one of the hallmarks of wisdom and is linked to other positive personality characteristics, such as openness to experience and a balance of introversion-extroversion (Pasupathi, Staudinger, \& Baltes, 2001; Staudinger, 1999; Staudinger, Lopez, \& Baltes, 1997). In other words, individuals who display a strong tendency to draw integrative 
meaning or life lessons from their memories should report optimal levels of adjustment.

The dimension of event content. There is a rich history, dating back to Adler, of analyzing memories for thematic content (for reviews, see Bruhn, 1984; Singer \& Salovey, 1993). More recently, researchers have proposed various systems for linking memory content to important goals, enduring concerns, and unresolved conflicts (Moffitt \& Singer, 1994; Pillemer, 2001; Singer \& Salovey, 1993; Tomkins, 1987; Woike, 1995; Woike, Gersekovich, Piorkowski, \& Polo, 1999).

In an early descriptive study, Pillemer, Rhinehart, and White (1986) found that themes revolving around recreation, romance, and family life were prevalent in the autobiographical memories of students after transition to college. Core themes of interactions, motives, and wishes in autobiographical memories, scored by Luborsky's (1990) method, may predict self-esteem and its fluctuations (Thorne \& Michaelieu, 1996). Scores on the agency and communion motives in the TAT narratives of participants are congruent with the thematic content of their daily memory diaries (Woike \& Polo, 2001). A recent method of scoring memories for themes of redemption and contamination yielded associations with well-being and adjustment (McAdams, Reynolds, Lewis, Patten, \& Bowman, 2001).

In contrast to these thematic approaches, Thorne and McLean (2001) developed, empirically, a scoring system for a range of mutually exclusive types of events reflected in self-defining memories. As described later in this paper, the latter system was adapted for the purposes of the current study and coded for relationships, achievements, and physical threat, among other content categories.

The advantage of this event-content system is that it minimizes the inferences raters need to make about the implied themes of the memory; it allows for a reasonable objective rendering of the "manifest" content of the memory, which promotes a more straightforward comparison among individuals. In the current study, the use of this method allowed for evaluation of correlations between individuals' tendency to recall event memories associated with success, whether in relationship or achievement, and personal adjustment and levels of distress.

The dimension of affect. In our previous research on affective responses to self-defining memories, we have measured participants' 
rating of how a memory makes them feel at the time of recall, and these affect ratings have been linked to the memories' relevance to the nature of personal strivings (approach and avoidance) and their attainment and non-attainment (Moffitt \& Singer, 1994; Singer, 1990). It is worth noting that affect is measured, not simply for valence (positive or negative), but for the intensity of the affective tone as well.

An area of personality difference that has been consistently examined in studies of memory affect is how recall of affective memories relates to individuals' proneness to depression (Campbell, Matt, \& Vazquez, 1992; Blaney, 1986; Singer \& Salovey, 1988; Rusting, 1998). Individuals who are depressed have demonstrated difficulty in using more positive autobiographical memories for mood repair (Josephson, Rose, \& Singer, 1999-2000; Rusting \& DeHart, 2000). In the current study, we related participants' ratings of their affective responses to memories to a trait measure of distress.

\section{A Way to Approach Personality Adjustment}

In order to demonstrate how self-defining memory characteristics may reflect aspects of personality adjustment, defensiveness, and distress, we selected the Weinberger Adjustment Inventory as a psychometrically sound and theoretically meaningful measure of these personality dimensions. The Weinberger Adjustment Inventory (WAI; Weinberger, 1997, 1998; Weinberger \& Schwartz, 1990) measures two primary dimensions of Self-Restraint and Subjective Expression of Distress. The Self-Restraint dimension covers intrapersonal (impulse control), interpersonal (suppression of aggression and consideration of others), and communal (responsibility) aspects of socialization. Low restraint is characteristic of young children or individuals who do not regulate their impulses and affects successfully and is associated with problem behavior such as drug use, delinquency, and aggression (for summaries, see Farrell \& Sullivan, 2000; Weinberger, 1998). Overcontrol is the result of socialization and can be considered more adaptive; however, individuals who are best socially and emotionally adapted should show moderate selfrestraint as they manage affect skillfully and do not become rigid or overly intellectualized (Asendorpf \& van Aken, 1999; Hart, Hofmann, Edelstein, \& Keller, 1997; Weinberger \& Schwartz, 1990). 
The Subjective Experience of Distress dimension has the subscales of trait anxiety, depression, low well-being, and low self-esteem, and it captures the self's own appraisal of its status in relation to personal goals as well as to external sources of threat. Weinberger $(1996,1997)$ has provided validation of the Distress dimension, as have independent researchers (e.g., Garner, Steiner, Huckaby, \& Kohler, 1998).

In addition to measuring dimensions of Self-Restraint and Distress, the short form of the WAI includes a Repressive Defensiveness scale. This scale measures repression, defined as the avoidance of negative affect and a positive self-presentation, independent of actual levels of distress (Weinberger \& Davidson, 1994). Turvey and Salovey (1994) compared it to four other previous defensiveness and repression scales and found it to be optimal in terms of internal consistency, normal distribution, and efficiency to administer.

\section{Hypotheses}

Specificity. (1). There will be a negative linear relationship between scores on WAI-SF Distress and the number of specific self-defining memories written down by individuals. (2). Since in some Williams studies and related research, only the specificity of positive memory narratives was related to depression, there will be a negative linear relationship between scores on WAI-SF Distress and the number of specific positive memories. (3). According to the repression hypothesis of nonspecific recall (Singer \& Salovey, 1993), there will be a negative linear relationship between scores on WAI-SF Repressive Defensiveness and the number of specific self-defining memories.

Integrative Meaning. (4). Since Weinberger has identified a relationship between moderate self-restraint and enhanced psychological adjustment, we would predict a curvilinear relationship between scores on WAI-SF Self-Restraint and the number of integrative selfdefining memories, with individuals scoring moderately on SelfRestraint producing the highest number of integrative memories, and individuals scoring low and high on Self-Restraint producing lower numbers of integrative memories.

Content. (5). There will be a positive linear relationship between WAI-SF Distress and the number of self-defining memories of threat, disrupted relationships, and failure. The inverse relationship 
to Distress should be observed for the number of memories associated with success in relationships and achievements.

Affect. (6). WAI-SF Distress scores should correlate in the expected directions with average negative and positive affect ratings of the memories.

\section{METHOD}

\section{Participants}

Participants were 108 undergraduates, of whom 104 (80 women and 24 men) completed the materials. They ranged from 17-22 years of age $(M=18.78)$ and were ethnically homogenous $(90 \%$ White, $4 \%$ Black, $2 \%$ Asian American, 2\% Latino/Latina, and 2\% other). They were offered class credit for participating in "a study of personal memories."

\section{Procedure}

Participants signed up for one of eight evening sessions held in the same seminar room. Each person was asked to complete at his or her own pace a memory study packet, consisting of 10 Self-Defining Memory Tasks, 10 Memory Rating Sheets, and the Weinberger Adjustment Inventory-Short Form (WAI-SF).

\section{Measures and instruments}

The self-defining memory task and memory rating sheets. Participants were asked to generate 10 self-defining memories and then go back and rate each one of them on 12 emotions, vividness, and importance. (For a history of the research done with the task, see Singer and Salovey, 1993). In more recent research with this measure, we have added an explicit request for memories that are "important to an enduring theme, issue, or conflict" in the participant's life and also connect to other similar memories. As in previous studies (e.g., Moffitt \& Singer, 1994), participants rated their memories on the basic emotions of happiness, sadness, anger, fear, surprise, shame, disgust, guilt, interest, and contempt (Izard, 1977) with pride and embarrassment added. Positive and Negative Affect were operationalized as averaged combined scores on positive or negative self-rated emotions that tended to cluster together in factor analyses.

The Weinberger Adjustment Inventory-Short Form is the 37-item version of the Weinberger Adjustment Inventory (WAI; Weinberger, 1997, 1998). It measures long-term personality functioning and has been validated with clinical and nonclinical populations. The dimensions are Distress (subscales: Anxiety, Depression, Low Self-Esteem, and Low Well-Being), Self-Restraint (subscales: Impulse Control, Suppression of 
Aggression, Consideration of Others, and Responsibility), and Repressive Defensiveness (covering denial of normative distress and claims of absolute restraint). WAI-SF Cronbach $\alpha$ for a nonclinical sample of 335 students (ages 18-30) were obtained from D. A. Weinberger (personal communication, March 6, 2000) as follows: .86 for Distress (12 items), .80 for Self-Restraint (12 items), and .79 for Repressive Defensiveness (11 items). The latter measure has been validated independently by Turvey and Salovey (1994). In the current study, Distress, Self-Restraint, and Repressive Defensiveness yielded respectively $\alpha=.90, .79$, and .67 $(N=104)$. (Single item deletions did not alter $\alpha$ for Repressive Defensiveness.)

The Classification System and Scoring Manual for Self-defining Memories (Singer \& Blagov, 2000; see Table 1) is a protocol that allows raters to be trained to score self-defining memories for specificity and meaning. It has already been partially validated (Blagov \& Singer, 2000; Blagov, Singer, \& Vergnani, 2002; Moffitt \& Singer, 1994; Singer \& Blagov, 2000; Singer \& Moffitt, 1991-1992). For the purposes of this study, specificity was operationalized as the number of specific (vs. nonspecific) selfdefining memories (out of 10). The scoring system discriminates reliably between subtypes of these two categories of specificity, but previous research has tended to use a dichotomy of specific vs. summary memories. Although there are types of specific narratives with generalized portions, it is the ability or inability of individuals to access this most detailed level (event-specific knowledge in the SMS model) that was relevant to the current investigation. In the dimension of integrative meaning, the scoring system (Singer \& Blagov, 2000) discriminates between integrative and nonintegrative self-defining memories, each category having two subtypes. Since both types of integrative narratives involve stepping back from the memory and extracting a lesson that transcends the remembered events, both types can be viewed as integrative life reflection, and so a total count for integrative memories (out of 10) per individual was used to operationalize meaning.

The Manual for Coding Events in Self-Defining Memories (Thorne \& McLean, 2001) is an original protocol that allows the scoring of selfdefining memories for event content. The system is under testing for interrater reliability and construct validity. As adapted for the present purposes, there were nine event types. Narratives of threat were about deaths, accidents, assaults, illness, and other concerns with personal safety. (There were five subcategories: threat to someone else, accident/ illness of self, physical assault to self, sexual assault to self, and not classifiable.) Narratives of disrupted relationships included breakup, divorce, separation, and interpersonal conflict. Undisrupted relationships focused on relationships without conflicts. Achievement/mastery narra- 


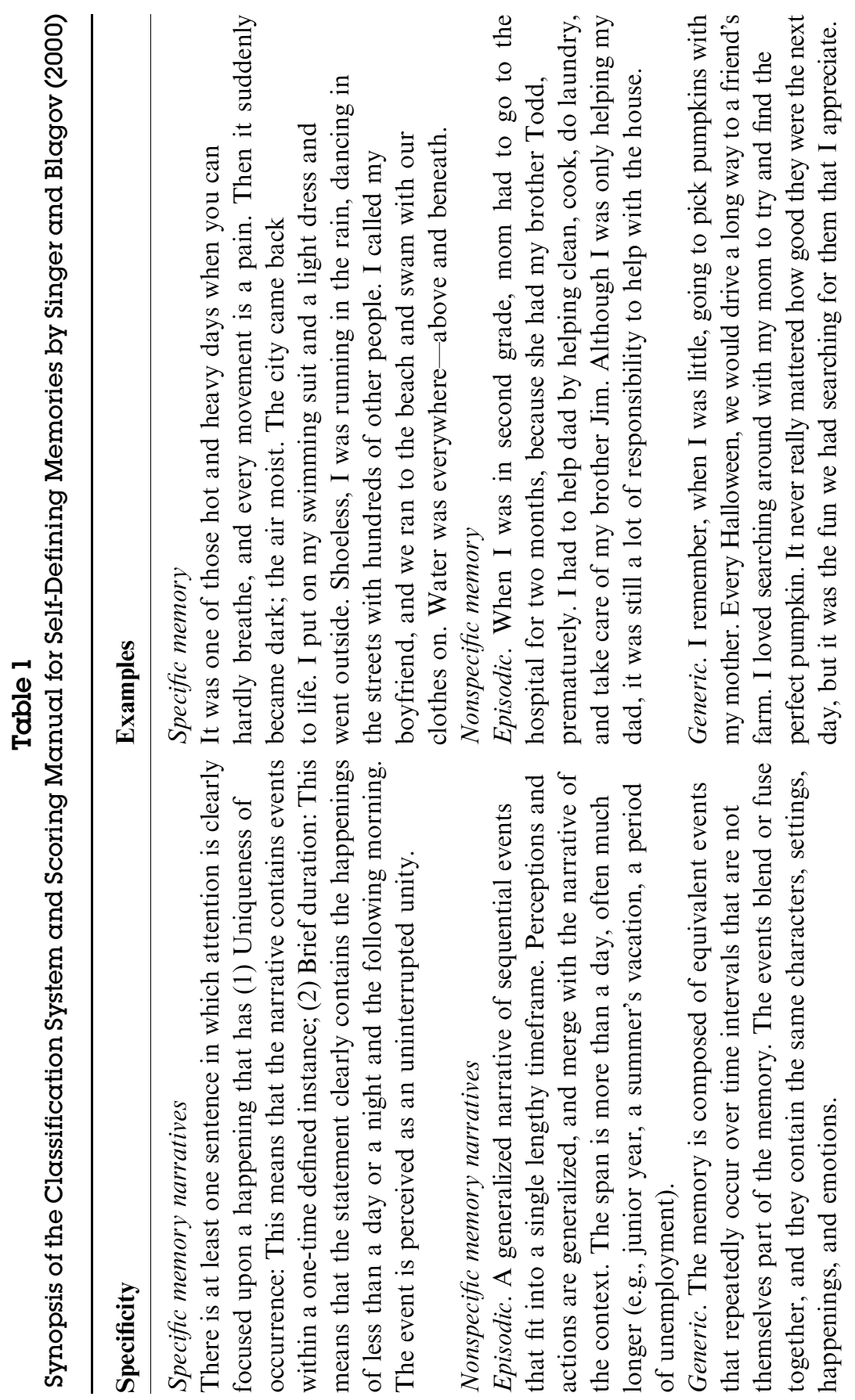



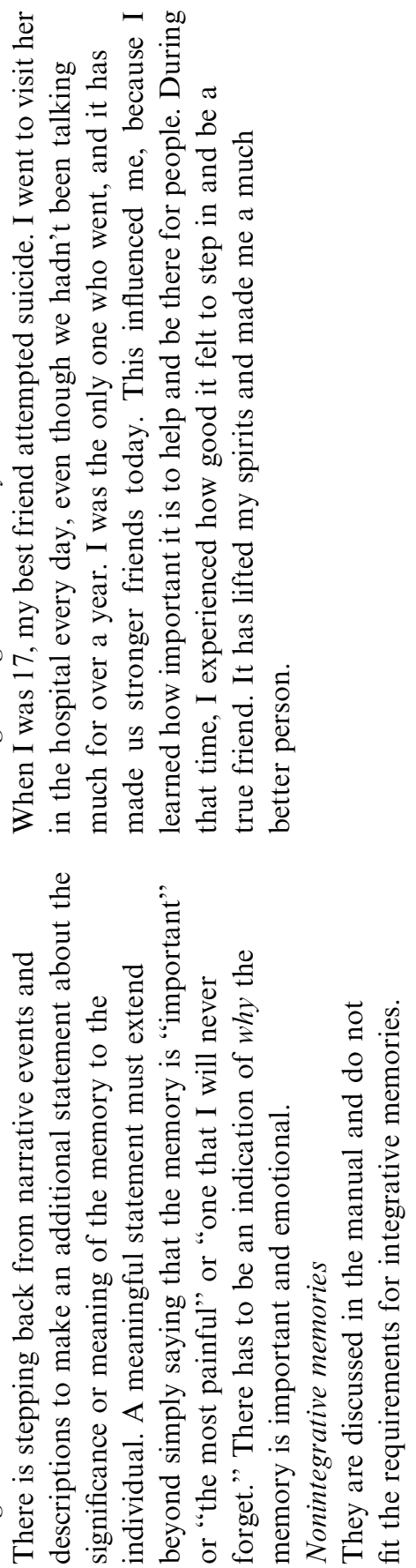
tives (e.g., winning competitions, learning skills, getting into college, becoming popular) emphasized success and ended on a positive note, whereas failure narratives emphasized frustrated attempts at achievement and ended in a negative way. Narratives of recreation/exploration were about play and enjoyment. Guilt/shame narratives revolved around the issue of doing right or wrong (e.g., remorse for stealing). Drugs/alcohol narratives were exclusively about substance use for recreation, thrill, or suicide. The last category was "event not classifiable."

\section{Reliability and Scoring of Specificity and Integrative Meaning for the Self-Defining Memories}

Reliability information for the self-defining memory scoring system is available through the Singer and Blagov (2000) manual; specificity reliability ranges from $\kappa=.80-.98$, depending on how many levels of specificity are evaluated, and integrative vs. nonintegrative memory scoring yields a $\kappa=.70$.

In the current study, 1040 self-defining memories were scored for specificity and integrative meaning in parallel by the authors. After every 200 memories, reliability was computed and disagreements were discussed. In order to reduce biases, the transcripts were mixed so that each participant's memories were maximally dispersed. The overall agreement was $\kappa=.83$ for two levels of specificity $(93.9 \%)$ and $\kappa=.72$ for meaning $(88.4 \%)$ before discussion.

Content. Two undergraduates under training as part of a separate project used the Manual for Coding Events in Self-Defining Memories by Thorne and McLean (2001) to score 500 self-defining memories for content. Cohen's $\kappa=.663$ ( $71 \%$ agreement) for all 13 categories before discussion suggested that acceptable reliability could be attained. The rater with the most training scored the remaining 540 self-defining memories. In order to reduce biases, the transcripts from each participant were dispersed among the rest. Since there were only 10 self-defining memories per participant, not all content variables yielded acceptable distributions of event frequency per participant.

Four were retained: threat (all types combined, range $0-8, M=1.46$, $S D=1.30$ ), undisrupted relationships (range 0-7, $M=1.54, S D=1.55$ ), disrupted relationships (range $=0-6, M=1.56, S D=1.35$ ), and achievement $/$ mastery $($ range $=0-7, M=2.25, S D=1.62)$.

\section{Data Reduction (Affect)}

The mean scores on the Memory Rating Sheets per participant were tabulated, and a factor analysis with varimax rotation was executed to 
Table 2

Factor Analysis of Mean Scores for 12 Emotions across 10 Self-Defining Memories $(N=104)$

\begin{tabular}{lcc}
\hline & Negative Affect & Positive Affect \\
\hline Happy & -.556 & $.656^{\mathrm{a}}$ \\
Sad & $.758^{\mathrm{a}}$ & -.027 \\
Angry & $.816^{\mathrm{a}}$ & .065 \\
Fearful & .531 & .549 \\
Surprised & .349 & $.785^{\mathrm{a}}$ \\
Ashamed & $.885^{\mathrm{a}}$ & -.079 \\
Disgusted & $.834^{\mathrm{a}}$ & -.018 \\
Guilty & $.848^{\mathrm{a}}$ & -.090 \\
Interested & -.051 & $.823^{\mathrm{a}}$ \\
Embarrassed & $.722^{\mathrm{a}}$ & .165 \\
Contemptful & $.541^{\mathrm{a}}$ & .382 \\
Proud & $-.297^{\mathrm{a}}$ & $.786^{\mathrm{a}}$ \\
\hline
\end{tabular}

$N=104$. Principal component analysis with varimax rotation.

${ }^{a}$ Loadings higher than .400 that loaded on one and only one factor were retained. The one exception was happy, which loaded - .556 on the Negative Affect factor as well, but was retained due to its pivotal importance as an affect variable.

determine the underlying grouping of the 12 basic emotions. Two factors emerged, based on variables that loaded at least .40 on one and only one factor (Table 2): Negative Affect (the mean for sad, angry, ashamed, disgusted, guilty, embarrassed, and contemptful) and Positive Affect (the mean for happy, surprised, interested and proud). Although happy loaded on both factors, its loading was higher on Positive Affect (.656 vs. - .556) and it was retained there, given its central importance to positive emotion. The two factors were internally consistent, yielding Cronbach's $\alpha=.788$ for Positive Affect and $\alpha=.891$ for Negative Affect. Identifying positive specific memories. The $Z$-score on the variable "sad" was subtracted from the $Z$-score on "happy" for each memory. The number of memories yielding a positive value that had also been scored as specific memories was counted for each participant.

\section{RESULTS}

Women and men did not differ on memory or personality-related variables in independent $t$-tests. Subsequent analyses were collapsed across gender. Compared to normative means based on age-matched college samples for WAI-SF Distress $(M=28.2, S D=8.2, N=340)$ 
and Self-Restraint $(M=45.5, S D=6.9, N=340, \mathrm{D}$. A. Weinberger, personal communication, March 6, 2000), the sample scored higher on Distress, $t(102)=4.08, p<.001$, and Self-Restraint, $t(102)=7.01$, $p<.001$ (see descriptives in Table 3). These and all subsequent analyses were performed with the exclusion of one participant whose Self-Restraint score was an extreme outlier.

\section{Specificity}

Hypotheses $1 \& 2$. Contrary to the prediction, Distress did not correlate with memory specificity, $r(103)=.006, p=.95$ (see Table 3 ). However, it was inversely linked to the number of specific positive memories, $r(103)=-.319, p<.001$. To determine whether this relationship was primarily due to the affective quality of the memory or its specificity, we looked at partial correlations, first controlling for the sadness associated with the memory, and then controlling for memory specificity. The relationship diminished when controlling for sadness, $r(100)=-.147, p=.139$, but less so when controlling for specificity, $r(100)=-.265, p<.01$, suggesting that the relationship is due more to affect than the specificity of the memory narratives.

Hypothesis 3. As predicted, Repressive Defensiveness correlated with memory specificity, $r(103)=-.221, p<.05$, indicating that participants higher in repressive defensiveness recalled fewer specific memories. Yet, in obtaining this result, this relationship might be mediated by the number of words in the memory narratives. Perhaps defensive individuals simply wrote shorter memories that lacked imagery and detail due to their brevity. In fact, there was a marginally significant positive relationship between number of words and specificity $(r(103)=.165, p=.097)$. However, the correlation of Repressive Defensiveness with length in words was significant, but in the opposite direction; longer memory narratives correlated with higher Repressive Defensiveness scores, $r(103)=.201, p<.05$.

Is it possible then that defensive individuals provided intellectualized memories that used more words but less imagery? Support for this possibility comes from the negative correlation of specificity and integrative meaning, $r(103)=-.378, p<.001$, suggesting that individuals who provided more specific memories were less inclined to step back and offer lessons or insights. Additionally, Repressive Defensiveness correlated with integrative meaning, $r(103)=.218$, $p<.05$. To examine these relationships in more detail, we conducted 


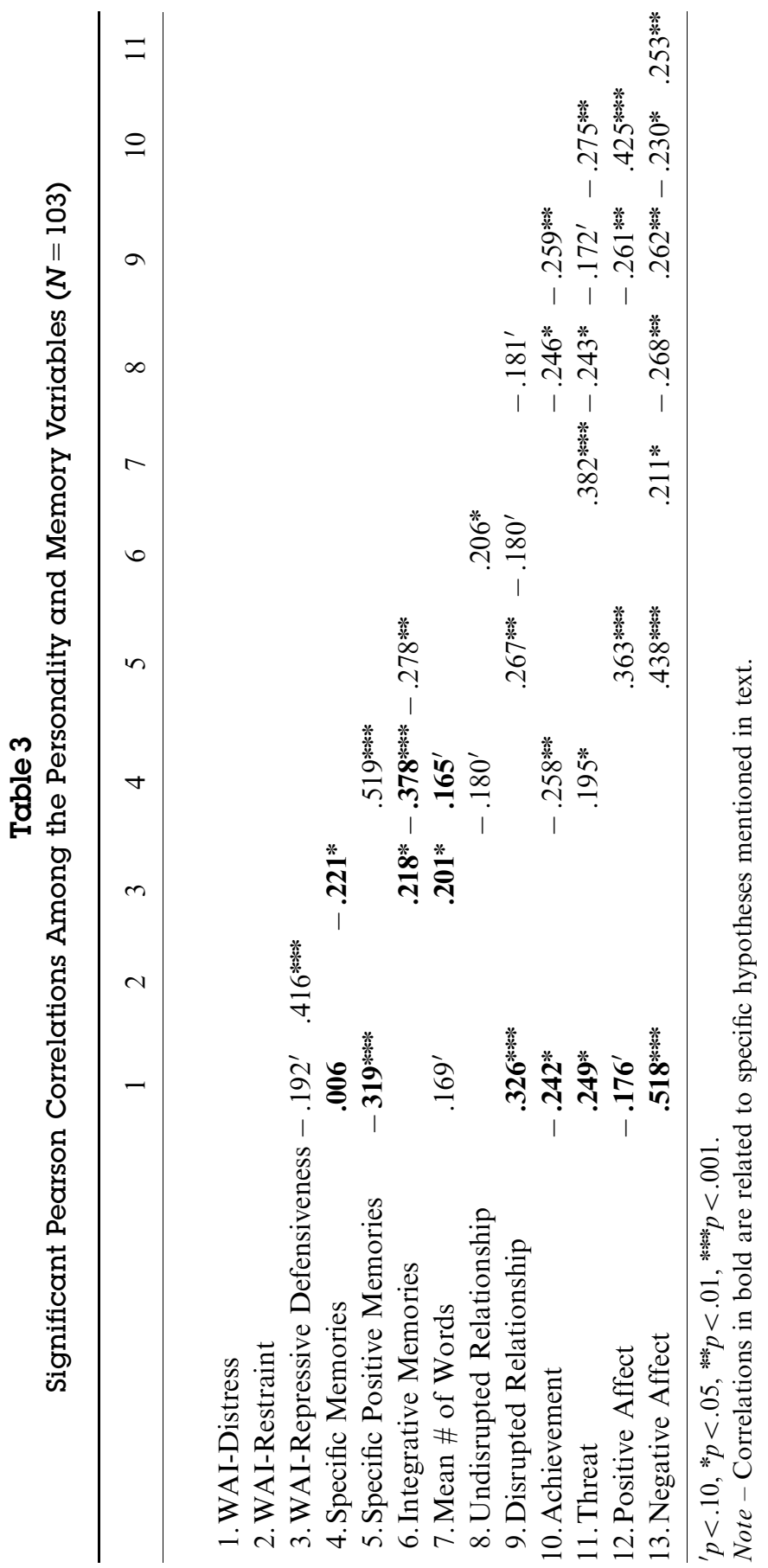


a linear regression, predicting Repressive Defensiveness from number of words, specificity, and integrative meaning. Only specificity and number of words were significant predictors $\left(A d j . R^{2}=.09\right.$, $\beta=-.22, p<.05 ; \beta=.22, p<.05$ respectively); therefore, integrative memories did not display an independent relationship to defensiveness.

Further mediational analyses, looking at regressions that alternated the predicted variable among Repressive Defensiveness, specificity, and integrative meaning, determined that the relationship between specificity and integrative meaning remained unchanged, even when controlling for Repressive Defensiveness.

\section{Meaning}

Hypothesis 4. In order to test the relationship of Self-Restraint to integrative memories, the sample was split into equal thirds of low, moderate, and high Self-Restraint. The one-way ANOVA with integration as the dependent variable and Self-Restraint as the predictor was significant, $F(2,100)=4.03, p=.021$ (see Figure 1). Pairwise comparisons were consistent with the predicted pattern in the number of integrative memories for the moderate $(M=3.97)$ vs. the low $(M=2.09, p=.006)$ and the high $(M=2.80, p=.083)$ SelfRestraint groups.

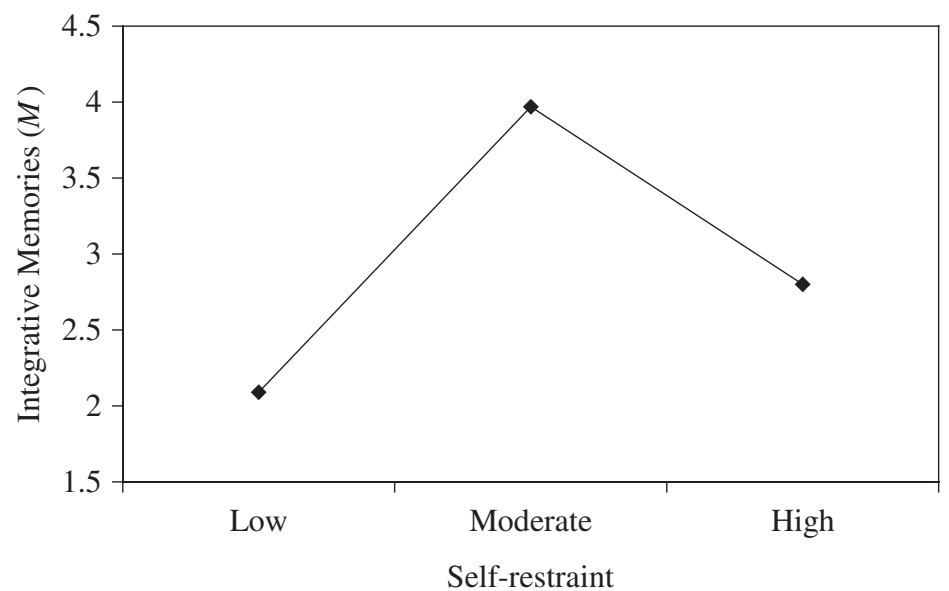

Figure 1

Self-restraint in a one-way ANOVA predicting integrative self-defining memories. Moderate levels of self-restraint are associated with an elevation of integrative memories. 


\section{Content}

Hypothesis 5. The number of disrupted relationship self-defining memories was linked to Distress, $r(103)=.326, p<.001$. Distress was also correlated with threat, $r(103)=.249, p<.01$, and achievement, $r(103)=-.242, p<.05$ (see Table 3 ). In a linear multiple regression predicting Distress from memory content, threat $(\beta=.291, p<0.01)$ and disrupted relationships $(\beta=.358, p<.001)$ emerged as the strongest predictors $\left(A d j . \quad R^{2}=.182\right)$. Entering Negative Affect about memories into the regression alongside the content variables did not change their relationship to Distress. A regression for Negative Affect about memories $\left(\right.$ Adj $\left.. R^{2}=.171\right)$ yielded undisrupted relationships $(\beta=-.233, p<.05)$, disrupted relationships $(\beta=.202, p<.05)$, and, marginally, threat $(\beta=.180, p=.097)$ and achievement $/$ mastery $(\beta=-.185, p=.098)$ as predictors.

Affect

Hypothesis 6. WAI-SF Distress was linked to memory Negative Affect, $r(103)=.518, p<.001$, and Positive Affect, $r(103)=-.176$, $p=.076$. The two memory affect variables were not correlated, $r(103)=-.044, p=.661$. Positive and Negative Affect about mem-

Table 4

Descriptive Statistics for the Personality and Memory Variables

\begin{tabular}{lrrrr}
\hline Variable & \multicolumn{1}{c}{$N$} & \multicolumn{1}{c}{$M$} & $S D$ & $\alpha$ \\
\hline Specific memory narratives (specificity) & 103 & 7.78 & 2.05 & \\
Integrative memory narratives (integration) & 103 & 2.93 & 2.84 & \\
Mean Positive Affect & 103 & 9.62 & 3.89 & .79 \\
Mean Negative Affect & 103 & 9.06 & 5.57 & .89 \\
Specific positive memories & 103 & 3.97 & 2.13 & \\
Mean length in words & 103 & 102 & 33.23 & \\
Mean memory age (years since memory) & 103 & 5.08 & 1.89 & \\
Mean memory vividness (0-6) & 103 & 4.63 & .63 & \\
Mean memory importance (0-6) & 103 & 4.38 & .73 & \\
Memories of undisrupted relationship & 103 & 1.53 & 1.56 & \\
Memories of disrupted relationship & 103 & 1.54 & 1.35 & \\
Memories of achievements & 103 & 2.25 & 1.63 & \\
Memories of threat combined & 103 & 1.48 & 1.30 & \\
WAI-SF Distress & 103 & 31.98 & 9.41 & .90 \\
WAI-SF Self-Restraint & 103 & 49.30 & 5.51 & .79 \\
WAI-SF Repressive Defensiveness & 103 & 26.21 & 6.22 & .67 \\
\hline
\end{tabular}


ories were unrelated to Self-Restraint, Repressive Defensiveness, or number of integrative memories.

\section{DISCUSSION}

The findings of this study have demonstrated that four dimensions of narrative memory can be meaningfully related to self-restraint, defensiveness, and levels of distress. In addition to confirming the reliability of the Singer and Blagov (2000) scoring manual for selfdefining memories, this investigation has demonstrated the validity of these scoring categories in identifying personality variation. It has also provided support for the Thorne and McLean (2001) event content scoring system, establishing further reliability of this system and demonstrating its linkage to measures of distress in personality.

\section{Narrative Specificity and Emotional Disturbance}

The descriptive findings for memory specificity were comparable to those of previous studies with nonclinical samples (e.g., Pillemer et al., 1986; Singer \& Moffitt, 1991-1992) in that specific self-defining memories were more common $(78 \%)$ than nonspecific ones $(22 \%)$, and the percentages were similar across studies.

In the current investigation, the number of specific self-defining memories per participant did not correlate with Distress on the WAI-SF (Weinberger, 1997, 1998), and so Hypothesis 1 (predicting a link between overgeneralization and distress, as previously suggested by Williams, 1996) was not supported. Although there was an association between Distress and specific positive self-defining memories, in support of Hypothesis 2, controlling for memory sadness rendered it nonsignificant. Therefore, the current study is inconclusive about the relationship of emotional distress to the narrative specificity of self-defining memories in a nondepressed sample. One methodological difference is that previous studies have tended to request either specific or positive memories, while we requested 10 spontaneously generated self-defining memories with no constraint on specificity or affective tone.

\section{Narrative Specificity and Repression}

The repression hypothesis for autobiographical memory overgeneralization states that motivated inhibition of specific negative recall 
also generalizes to positive event retrieval (Singer \& Salovey, 1993; Williams, 1996). In the current study, repressive defensiveness was negatively linked to the number of specific self-defining memories (Hypothesis 3). However, repressive defensiveness was not related to the affective quality of the memories. Together, these findings suggest that repression may be related not to what people remember and choose to report and not to how they report feeling about it, but to the way in which they structure their narrative reports. Perhaps, the initial repressive concern is to preempt "looking" at specific events altogether (by clinging to a nonspecific structure). Events that make it through this filter have been "sanitized" of vivid and selfthreatening imagery, regardless of the putative affect associated with them.

The keeping of unacceptable details and imagery out of the life story safeguards against anxiety, preserves self-esteem, and also makes the story more tellable in a socially conventional sense (Bruhn, 1984; McAdams, 1988, 1998). One of the reasons why victims of trauma employ defensive strategies may be that their experiences do not conform to familiar narrative formats and thus cannot be integrated into a coherent or socially sanctioned narrative that can be expressed internally or shared with others (Barclay, 1993, 1996).

The notion that narratives of memories may serve a defensive purpose is consistent with the SMS model (Conway \& PleydellPearce, 2000), according to which, control processes inhibit the emergence into consciousness of spontaneously activated autobiographical knowledge. It is possible that the avoidance of threatening memory imagery and specificity may be among the active goals that guide retrieval control processes at certain times, and, for some individuals, all the time. Future research should address causality in the relationship between repressiveness and narrative style developmentally and situationally. Behavioral measures of repressive coping should supplement assessment through self-report.

\section{Meaning, Adjustment, and Personality Organization}

In Weinberger's (1998) framework, moderate self-restraint is a developmental achievement and a sign of emotional maturity and personal adjustment. From a narrative perspective, maturity is synonymous with the ability to engage in autobiographical reasoning in order to construct a coherent and generative life story 
(Habermas \& Bluck, 2000; McAdams, 2001; Staudinger, 1999, 2001; Thorne, 2000). A curvilinear relationship between self-restraint and the tendency toward self-defining memory integration was predicted in Hypothesis 4, and the prediction was supported. Individuals with moderate self-restraint scores wrote down more integrative selfdefining memories than did the low and the high self-restraint groups. Further studies should address the directionality of the relationship between this and other aspects of emotional adjustment and the readiness with which people seek and report personal meaning in their memories.

One finding in the current study was that high self-restraint individuals more closely resembled moderate self-restraint individuals in terms of integrative memories than they matched low selfrestraint individuals. Weinberger (1998) wrote that high self-restraint, though not optimal, is indeed more advanced than the impulsivity of low self-restraint. Although the causal relationships remain unclear, we favor the following interpretation. Meaning making and the construction of integrative self-defining memories are strategies that help people cope with negative emotions. Being more impulsive and less socialized into cultural narrative norms, low-restraint individuals rarely step back to think about the meaning of their actions and memories. Moderate self-restraint suggests an ability to acknowledge and regulate emotions, making it possible for individuals to engage in high-order processing of their emotional memories. High self-restraint, although reflecting an ability to step back from impulsive action, is associated with a desire to conform to cultural norms, as well as a rigid and overcontrolled coping style. Thus, a question for future research is whether the kinds of integrative statements produced by individuals high in self-restraint are genuine insights or more of the order of conventional morals or intellectualizations.

Social-emotional competence measured by WAI-SF Self-Restraint clearly is not the only factor that predicts the presence of a salient narrative identity in young adults. Intelligence and contextual factors in development may be important contributors (Staudinger et al., 1997, 1998). Additional investigations also might link the concept of integrative meaning to the work of Pennebaker (e.g., Pennebaker \& Segal, 1999), which has emphasized that the capacity to provide a meaningful framework for personal disclosure enhances its positive health effects. 


\section{Thematic Content and Distress}

This project provided further validation of Thorne and McLean's (2001) taxonomy of the content of self-defining memories. Themes of disrupted relationships and threat (and, to a lesser extent, the absence of achievement/mastery) predicted Distress on the WAISF. One might ask why memories about undisrupted relationships did not yield a negative correlation with Distress. These memories were often memories that involved parents and, though they did not explicitly highlight conflict, they displayed higher levels of ambivalence and mixed affect. However, in general, individuals experiencing higher distress in their lives showed a tendency to recall events congruent with their negative mood (Blaney, 1986; Singer \& Salovey, 1988).

\section{Relationships Among the Dimensions}

It is reasonable to speculate about how these different dimensions of memory narratives function independently or interactively to regulate affect and convey meaning to the self. Interestingly, both memory specificity and integrative meaning were largely independent of event content and affect. Event content and affect were related in a predictable manner, with memories about success and failure in relationships and achievements corresponding to positive and negative affect, respectively.

A strong negative relationship existed between specificity and integrative meaning. Yet regression analysis revealed that only specificity, and not integrative meaning, predicted repressive defensiveness. Further, the relationship between specificity and integrative meaning persisted, even controlling for defensiveness. This pattern of results suggests that participants who tended to supply memories that were summarized and not linked to a single event also drew more generalizations or lessons from these memories. These same individuals also tended to show higher levels of defensiveness, but their defensiveness was linked to their summarizing tendency, not their efforts at meaning making.

This finding suggests the interpretation that cognitive abstraction about a memory can serve two critical, but relatively independent, functions. Keeping events at a high level of generality may indeed serve a protective function in regulating affect and threatening information. At the same time, the ability to see linkage among 
discrete events and blend them into a summarized memory may facilitate meaning making and self-understanding. Accordingly, individuals who can achieve specificity and rich imagery in a recollection, while simultaneously extracting the integrative meaning from that same memory, may accomplish the dual feat of getting maximal affective and cognitive value out of an experience. Returning to the second client at the beginning of this article, her ability to recall the specific detail of her chilly February walk, but also to see its relevance for her current self-understanding, suggests she may have been able to make use of this memory both emotionally and cognitively in her pursuit of insight and growth (Singer \& Blagov, in press b).

\section{The Role of Self-Defining Memories in the Personality System}

The healthy adult self has the ability to search autobiographical knowledge and to construct autobiographical memories in order to inform its progress toward currently active goals (Barclay, 1994; Conway, 1996). The self conducts its search at the most general and abstract level and, as thematic categories relevant to the current goals are found, the search proceeds toward specific experiences. In adolescence, a more sophisticated process of autobiographical reasoning becomes possible as memories are elaborated upon and deliberately used as sources of abstract knowledge and lessons (Bluck \& Habermas, 2001; Thorne, 2000). Repetitive, vivid, and emotionally intense memories that are tied to the enduring concerns of the working self become likely candidates for this type of selfreflection. The abstract knowledge from these self-defining memories becomes integrated with other semantic memories about the self and gives rise to the life story schema, which is a permanent but evolving index of lifetime periods and important themes and concerns (Bluck $\&$ Habermas, 2001). With age, the life story schema gains increasing importance with respect to its ability to influence the working self as a source of motivation and wisdom in selecting parts of the self for particular scrutiny (Staudinger, 1999). Figure 2 presents the framework visually.

The specificity of self-defining memory narratives reflects their temporal organization, imagery, and degree of detail, as determined by the search process across levels of autobiographical knowledge. Control processes in working memory influence the degree of 


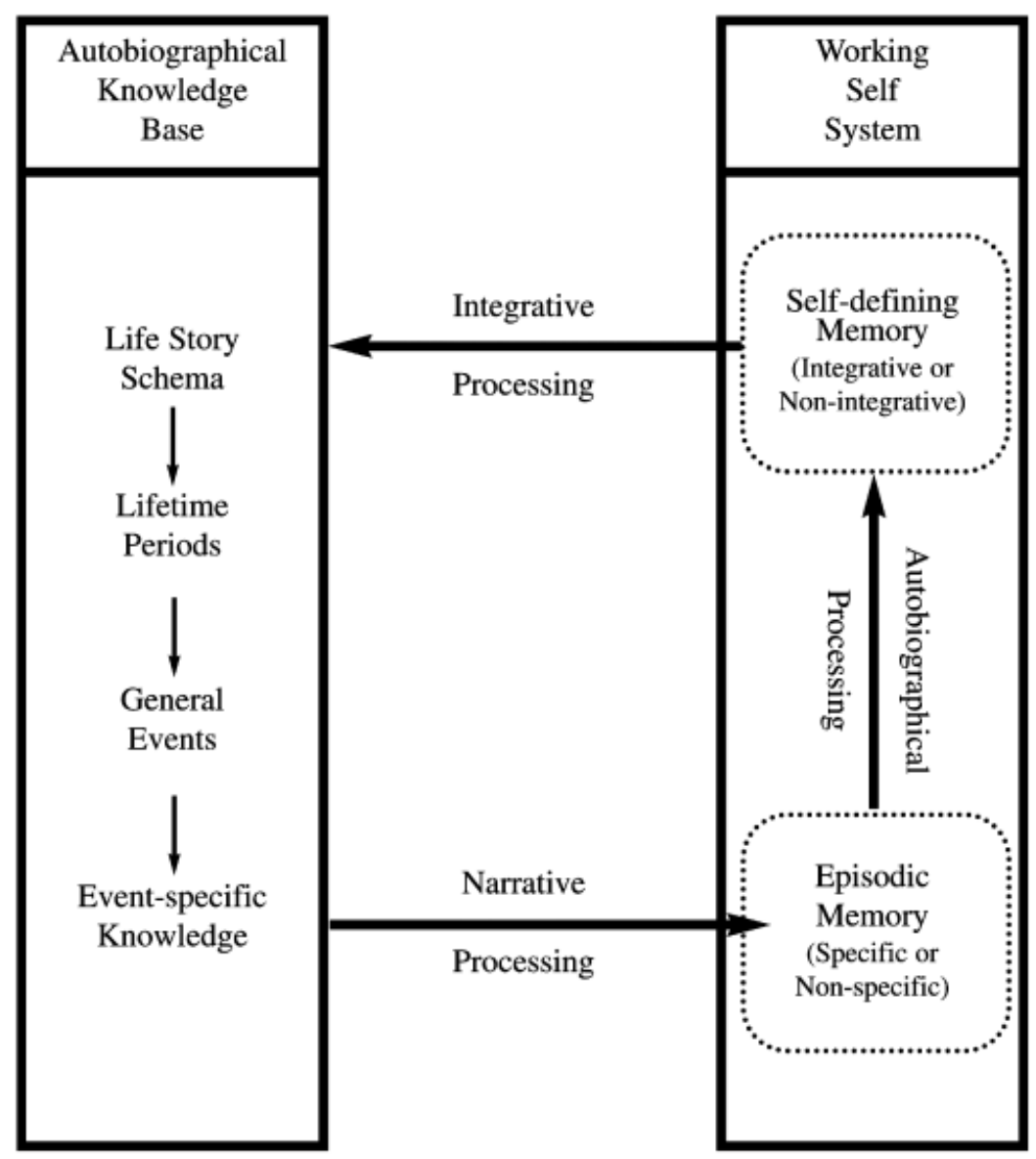

Figure 2

A model of the role of the life story schema and self-defining memories in the adult self-memory system. Episodic memories subject to autobiographical processing become self-defining. They can yield abstracted information that may be integrated into the life story schema. For simplicity, all pathways through which the working self can access the autobiographical knowledge base and the feedforward pathway from the life story schema to the working self have been omitted.

specificity that a given search will yield. The current study supports the repression hypothesis of overgeneralization in autobiographical memory, which suggests that defensive efforts to protect the self from emotional threat initiates these control processes to curtail the 
search for specific memories. However, other sources of overgeneralization, whether due to mood state, fatigue, or cognitive damage, are likely to exist.

The meaning of self-defining memories is their integrative quality, or the extent to which the narrative contains abstracted knowledge or lessons about the self or the world beyond the remembered events. Integrative self-defining memories may indicate that the individual engages in the construction of a life story and uses the past to inform a sense of identity. These memories may be indicative of rumination, intellectualization, or adaptive coping based on constructive learning about one's self.

The event content of self-defining memories is their subject matter. It may indicate what kinds of events, interactions, and outcomes the individual is most motivated to attain or to avoid. It may also indicate what kinds of actual events from the past were most important in determining the current personality status. Studying the intrapersonal trends and interpersonal differences in the proposed dimensions of self-defining memories bridges together the study of cognitive processes in autobiographical memory and the study of narrative identity. It may also lead to insights about what constitutes a well-developed life story that promotes psychological growth, maturity, social-emotional adjustment, and wisdom.

\section{Limitations and Recommendations}

Sample. Compared to the normative data for their age group, the participants in our sample had higher Distress and Self-Restraint scores. It is possible that the large number of females in the current sample may account for this difference, given socialization forces that inhibit men from expressing distress and that reinforce women for adherence to convention and self-restraint. Both Weinberger's sample and the current sample were drawn from a college population of limited diversity. A study of a larger-scale community sample would help to provide a better reference point for the normative levels of Distress and Self-Restraint.

Design. The current findings linking autobiographical memory to personality are correlational. Future research may address the process of self-defining memory construction by manipulating forms of memory retrieval or the repressive and depressive context of the request. Research into process is important for theory building, but 
it can also inform psychotherapy practices, particularly with regard to personality assessment. There is great potential for future practical implications stemming from the self-defining memory research framework in light of the current evidence for linkage to adjustment. Additional enhancements may include sampling more than 10 memories, sampling over a period of time, during a life transition, or from clinical samples.

\section{CONCLUSIONS}

The combined cognitive-narrative framework for the study of autobiographical memory in personality has explanatory power, and this research project provided support for most predictions. Overall, the findings suggested that aspects of self-defining memories, measured objectively, corresponded to self-report data on aspects of personality and adjustment. The content of self-defining memories was related to emotional distress, narrative specificity was linked to repressive defensiveness, and the tendency of individuals to reflect upon the meaning of their memories corresponded to a measure of self-restraint and adjustment. The proposed framework for classifying self-defining memories along different dimensions can be applied productively in future studies of personality and autobiographical memory.

\section{REFERENCES}

Asendorpf, J. B., \& van Aken, M. A. (1999). Resilient, overcontrolled, and undercontrolled personality prototypes in childhood: Replicability, predictive power, and the trait-type issue. Journal of Personality \& Social Psychology, 77, $815-832$.

Barclay, C. R. (1993). Remembering ourselves. In G. M. Davies \& R. H. Logie (Eds.), Memory in everyday life. Advances in psychology, 100 (pp. 285-309). Amsterdam, Netherlands: North-Holland/Elsevier Science Publishers.

Barclay, C. R. (1994). Composing protoselves through improvisation. In U. Neisser \& R. Fivush (Eds.), The remembering self: Construction and accuracy in the self-narrative (pp. 55-78). New York: Cambridge University Press.

Barclay, C. R. (1996). Autobiographical remembering: Narrative constraints on objectified selves. In D. C. Rubin (Ed.), Remembering our past: Studies in autobiographical memory (pp. 94-125). Cambridge, MA: Cambridge University Press.

Bauer, J. J., \& Bonanno, G. A. (2001). I can, I do, I am: The narrative differentiation of self-efficacy and other self-evaluations while adapting to bereavement. Journal of Research in Personality, 35, 424-448. 
Blagov, P. S., \& Singer, J. A. (2000, October). Relationships between identity and social-emotional maturity: Self-defining memories, self-concept clarity, and selfrestraint. Paper presented at the meeting of the New England Psychological Association, Lewiston, Maine.

Blagov, P. S., Singer, J. A., \& Vergnani, M. (2002, March). Structure and meaning in autobiographical memories: A reliable scoring system. Poster presented at the meeting of the Eastern Psychological Association, Boston, MA.

Blaney, P. H. (1986). Affect and memory: A review. Psychological Bulletin, 99, 229-246.

Bluck, S., \& Habermas, T. (2001). Extending the study of autobiographical memory: Thinking back about life across the life span. Review of General Psychology, 5, 135-147.

Brittlebank, A. D., Scott, J., Williams, J. M. G., \& Ferrier, I. N. (1993). Autobiographical memory in depression: State or trait marker? British Journal of Psychiatry, 162, 118-121.

Bruhn, A. R. (1984). The use of early memories as a projective technique. In P. McReynolds \& C. J. Chelume (Eds.), Advances in psychological assessment, 6 (pp. 109-150). San Francisco: Jessey-Bass.

Campbell, W. K., Matt, G. E., \& Vazquez, C. (1992). Mood-congruent recall of affectively toned stimuli: A meta-analytic review. Clinical Psychology Review, 12 (2), 227-255.

Conway, M. A. (1996). Autobiographical knowledge and autobiographical memories. In D. C. Rubin (Ed.), Remembering our past: Studies in autobiographical memory (pp. 67-93). New York: Cambridge University Press.

Conway, M. A., \& Pleydell-Pearce, C. W. (2000). The construction of autobiographical memories in the self-memory system. Psychological Review, 107, 261-288.

Davies, G. M., \& Logie, R. H. (Eds.) (1993). Memory in everyday life. Advances in psychology, 100. Amsterdam, Netherlands: North-Holland/Elsevier Science Publishers.

Davis, P. J., \& Schwartz, G. E. (1987). Repression and the inaccessibility of affective memories. Journal of Personality and Social Psychology, 52, 155-162.

Debats, D. L., Drost, J., \& Hansen, J. (1995). Experiences of meaning in life: A combined qualitative and quantitative approach. British Journal of Psychology, 86, 359-375.

Farrell, A. G., \& Sullivan, T. N. (2000). Structure of the Weinberger Adjustment Inventory self-restraint scale and its relation to problem behaviors in adolescence. Psychological Assessment, 4, 394-401.

Garner, E. H., Steiner, H., Huckaby, W. J., \& Kohler, M. (1998). A comparison between the Weinberger Adjustment Inventory and the Minnesota Multiphasic Personality Inventory with incarcerated adolescent males. Child Psychiatry \& Human Development, 28, 273-285.

Habermas, T., \& Bluck, S. (2000). Getting a life: The emergence of the life story in adolescence. Psychological Bulletin, 126, 748-769.

Hart, D., Hofmann, V., Edelstein, W., \& Keller, M. (1997). The relation of childhood personality types to adolescent behavior and development: A longitudinal study of Icelandic children. Developmental Psychology, 33, 195-205. 
Izard, C. E. (1977). Human emotions. New York, NY: Plenum.

Jardine, K. F. (1999). Transitions of women counsellors-in-training: Self-defining memories, narratives, and possible selves. Dissertation, University of Victoria, British Columbia, Victoria, Canada.

Josephson, B. R., Rose, R. D., \& Singer, J. A. (1999-2000). Thought sampling after mood induction in depressed vs. non-depressed college students. Imagination, Cognition \& Personality, 19 (1), 27-37.

King, L. A., Scollon, C. K., Ramsey, C., \& May, T. (2000). Stories of life transition: Subjective well-being and ego development in parents of children with Down Syndrome. Journal of Research in Personality, 34, 509536.

Luborsky, L. (1990). A guide to the CCRT method. In L. Luborsky \& P. CritsChristoph (Eds.), Understanding transference: The Core Conflictual Relationship Theme method (pp. 15-36). New York, NY: Basic Books.

McAdams, D. P. (1988). Power, intimacy, and the life story: Personological inquiries into identity. New York: Guilford Press.

McAdams, D. P. (1995). What do we know when we know a person? Journal of Personality, 63, 365-396.

McAdams, D. P. (1998). The role of defense in the life story. Journal of Personality, 66, 1125-1146.

McAdams, D. P. (2001). The psychology of life stories. Review of General Psychology, 5, 100-122.

McAdams, D. P., Reynolds, J., Lewis, M., Patten, A. H., \& Bowman, P. J. (2001). When bad things turn good and good things turn bad: Sequences of redemption and contamination in life narrative and their relation to psychosocial adaptation in midlife adults and in students. Personality \& Social Psychology Bulletin, 27, 474-485.

McLean, K. C., \& Thorne, A. (in press). Late adolescents' self-defining memories about relationships. Developmental Psychology.

Moffitt, K. H., \& Singer, J. A. (1994). Continuity in the life story: Self-defining memories, affect, and approach/avoidance personal strivings. Journal of Personality, 62, 21-43.

Moffitt, K. H., Singer, J. A., Nelligan, D. W., Carlson, M. A., \& Vyse, S. A. (1994). Depression and memory narrative type. Journal of Abnormal Psychology, 103, 581-583.

Moore, R. G., Watts, F. N., \& Williams, J. M. G. (1988). The specificity of personal memories in depression. British Journal of Clinical Psychology, 27, 275-276.

Pasupathi, M., Staudinger, U. M., \& Baltes, P. B. (2001). Seeds of wisdom: Adolescents' knowledge and judgment about difficult life problems. Developmental Psychology, 37, 351-361.

Pennebaker, J. W., \& Seagal, J. D. (1999). Forming a story: The health benefits of narrative. Journal of Clinical Psychology, 55, 1243-1254.

Pillemer, D. B. (1998). Momentous events, vivid memories. Cambridge, MA: Harvard University Press.

Pillemer, D. B. (2001). Momentous events and the life story. Review of General Psychology, 5, 123-134. 
Pillemer, D. B., Rhinehart, E. D., \& White, S. H. (1986). Memories of life transitions: The first year in college. Human Learning, 5, 109-123.

Robinson, J. A. (1986). Autobiographical memory: A historical prologue. In D. C. Rubin (Ed.), Autobiographical memory (pp. 19-23). New York: Cambridge University Press.

Rusting, C. L. (1998). Personality, mood, and cognitive processing of emotional information: Three conceptual frameworks. Psychological Bulletin, 124, 165-196.

Rusting, C. L., \& DeHart, T. (2000). Retrieving positive memories to regulate negative mood: Consequences for mood-congruent memory. Journal of Personality and Social Psychology, 78, 737-752.

Salaman, E. (1970). A collection of moments: A study of involuntary memories. London: Longman.

Singer, J. A. (1990). Affective responses to autobiographical memory and their relationship to long-term goals. Journal of Personality, 58, 535-563.

Singer, J. A., \& Blagov, P. S. (2000, June). Classification system and scoring manual for self-defining autobiographical memories. Paper presented at the meeting of the Society for Applied Research on Memory and Cognition, Miami Beach, FL.

Singer, J. A., \& Blagov, P. S. (in press a). The integrative function of narrative processing: Autobiographical memory, self-defining memories and the life story of identity. In D. R. Beike, J. M. Lampinen, \& D. A. Behrend (Eds.), The self and memory. New York: The Psychology Press.

Singer, J. A., \& Blagov, P. S. (in press b). Self-defining memories, narrative identity, and psychotherapy: A conceptual model, empirical investigation, and case report. In L. Angus \& J. McLeod (Eds.), The handbook of narrative and psychotherapy: Practice, theory, and research. Thousand Oaks, CA: Sage Press.

Singer, J. A., \& Bluck, S. (2001). New perspectives on autobiographical memory: The integration of narrative processing and autobiographical reasoning. Review of General Psychology, 5, 91-99.

Singer, J. A., \& Moffitt, K. H. (1991-1992). An experimental investigation of specificity and generality in memory narratives. Imagination, Cognition \& Personality, 11, 233-257.

Singer, J. A., \& Salovey, P. (1988). Mood and memory: Evaluating the network theory of affect. Clinical Psychology Review, 8, 211-251.

Singer, J. A., \& Salovey, P. (1993). The remembered self: Emotion and memory in personality. New York: Free Press.

Staudinger, U. M. (1999). Older and wiser? Integrating results on the relationship between age and wisdom-related performance. International Journal of Behavioral Development, 23, 641-664.

Staudinger, U. M. (2001). Life reflection: A social-cognitive analysis of life review. Review of General Psychology, 5, 148-160.

Staudinger, U. M., Lopez, D. F., \& Baltes, P. B. (1997). The psychometric location of wisdom-related performance: Intelligence, personality, and more? Personality and Social Psychology Bulletin, 23, 1200-1214.

Staudinger, U. M., Maciel, A. G., Smith, J., \& Baltes, P. B. (1998). What predicts wisdom-related performance? A first look at personality, intelligence, and facilitative experiential contexts. European Journal of Personality, 12, 1-17. 
Thorne, A. (2000). Personal memory telling and personality development. Personality and Social Psychology Review, 4, 45-56.

Thorne, A., \& McLean, K. (2001). Manual for coding events in self-defining memories. Unpublished manuscript. Department of Psychology, University of California - Santa Cruz.

Thorne, A., \& Michaelieu, Q. (1996). Situating adolescent gender and self-esteem with personal memories. Child Development, 67, 1374-1390.

Tomkins, S. S. (1987). Script theory. In J. Aranoff, A. I. Rabin, \& R. A. Zucker (Eds.), The emergence of personality (pp. 147-216). New York: Springer Publishing.

Turvey, C., \& Salovey, P. (1994). Measures of repression: Converging on the same construct? Imagination, Cognition \& Personality, 13, 279-289.

Weinberger, D. A. (1996). Distorted self-perceptions: Divergent self-reports as statistical outliers in the multi-method assessment of children's social-emotional adjustment. Journal of Personality Assessment, 66, 126-143.

Weinberger, D. A. (1997). Distress and self-restraint as measures of adjustment across the life span: Confirmatory factor analyses in clinical and non-clinical samples. Psychological Assessment, 9, 132-135.

Weinberger, D. A. (1998). Defenses, personality structure, and development: Integrating psychodynamic theory into a typological approach to personality. Journal of Personality, 66, 1061-1080.

Weinberger, D. A., \& Davidson, M. N. (1994). Styles of inhibiting emotional expression: Distinguishing repressive coping from impression management. Journal of Personality, 62, 587-613.

Weinberger, D. A., \& Schwartz, G. E. (1990). Distress and restraint as superordinate dimensions of self-reported adjustment: A typological perspective. Journal of Personality, 58, 381-417.

Williams, J. M. G. (1996). Depression and the specificity of autobiographical memory. In D. C. Rubin (Ed.), Remembering our past: Studies in autobiographical memory (pp. 244-267). New York: Cambridge University Press.

Williams, J. M. G., \& Broadbent, K. (1986). Autobiographical memory in suicide attempters. Journal of Abnormal Psychology, 95, 144-149.

Williams, J. M. G., \& Dritschel, B. H. (1988). Emotional disturbance and the specificity of autobiographical memory. Cognition and emotion, 2 (3), 221-234.

Williams, J. M. G., \& Scott, J. (1988). Autobiographical memory in depression. Psychological Medicine, 18, 689-695.

Woike, B. A. (1995). Most-memorable experiences: Evidence for a link between implicit and explicit motives and social cognitive processes in everyday life. Journal of Personality and Social Psychology, 68, 1081-1091.

Woike, B. A., Gersekovich, I., Piorkowski, R., \& Polo, M. (1999). The role of motives in the content and structure of autobiographical memory. Journal of Personality and Social Psychology, 76, 600-612.

Woike, B. A., \& Polo, M. (2001). Motive-related memories: Content, structure and affect. Journal of Personality, 69, 391-415. 


\section{2}


This document is a scanned copy of a printed document. No warranty is given about the accuracy of the copy. Users should refer to the original published version of the material. 